\title{
PENGARUH PELARUT TERHADAP KARAKTERISTIK NANOPARTIKEL TITANIUM DIOKSIDA $\left(\mathrm{TiO}_{2}\right)$
}

\author{
Atik Setyani $^{1)}$, Emas Agus Prastyo Wibowo ${ }^{1)}$ \\ ${ }^{1)}$ Program Studi Kimia, FMIPA Universitas Negeri Semarang \\ Email: setyaniatikatric@gmail.com, emasagus@ymail.com
}

\begin{abstract}
ABSTRAK
Tujuan penelitian ini adalah untuk membandingkan jenis pelarut dalam proses pembentukan nanopartikel titanium dioksida dengan metode sol gel. Hasil karakterisasi dengan X-Ray Diffraction (XRD) menunjukkan bahwa penggunaan pelarut berpengaruh terhadap kristalinitas dan fasa material yang terbentuk. Berdasarkan Joint Committee on Powder Diffraction Standards (JCPDS) card nomor 84-1286 menunjukkan difraktogram nano $\mathrm{TiO}_{2}$ hasil sintesis sebagian besar merupakan fasa anatas. Hal ini terlihat dari nilai 2 teta yang diperoleh yaitu $24,45^{\circ} ; 47,29^{\circ}$; $53,18^{\circ} ; 61,64^{\circ}$ untuk fasa anatas dan $54,65^{\circ} ; 74,16^{\circ}$ untuk fasa rutil. Hanya saja persentase fasa anatas pada nano $\mathrm{TiO}_{2}$ menggunakan pelarut metanol lebih besar jika dibandingkan dengan hasil nano $\mathrm{TiO}_{2}$ dengan pelarut etanol. Berdasarkan perhitungan ukuran partikel nano $\mathrm{TiO}_{2}$ menggunakan persamaan Debye- Scherer didapatkan ukuran nano $\mathrm{TiO}_{2}$ menggunakan metanol sebesar $13.78 \mathrm{~nm}$ sedangkan nano $\mathrm{TiO}_{2}$ menggunakan etanol sebesar $34.26 \mathrm{~nm}$.
\end{abstract}

Kata Kunci: Pelarut, sol-gel, titanium dioksida

\section{EFFECT OF SOLVENTS ON THE CHARACTERITICS OF NANOPARTICLES TITANIUM DIOXIDE $\left(\mathrm{TiO}_{2}\right)$}

\begin{abstract}
The purpose of this study was to compare the type of solvent in the process of formation of titanium dioxide nanoparticles with sol gel method. X-Ray Diffraction (XRD) characterization results indicate that the use of solvent effect on crystallinity and phase material formed. Based Joint Committee on Powder Diffraction Standards (JCPDS) 84-1286 card numbers show diffractogram nano $\mathrm{TiO}_{2}$ synthesized largely a anatas phase. This can be seen from a value of 2 theta obtained by the $24,45^{\circ} ; 47,29^{\circ} ; 53,18^{\circ} ; 61,64^{\circ}$ to phase anatas and $54,65^{\circ} ; 74,16^{\circ}$ for rutile phase. Only a small percentage of the nano $\mathrm{TiO}_{2}$ anatase phase using methanol solvent is greater when compared with the results of nano $\mathrm{TiO}_{2}$ with ethanol. Based on the calculation of nano $\mathrm{TiO} 2$ particle size using equation Debye- Scherer obtained nanosized $\mathrm{TiO}_{2}$ using methanol amounted to $13.78 \mathrm{~nm}$ while the nano $\mathrm{TiO}_{2}$ using ethanol amounted to $34.26 \mathrm{~nm}$.
\end{abstract}

Keywords: Solvent, sol-gel, titanium dioxide

\section{PENDAHULUAN}

Perkembangan teknologi nano material menunjukkan kontribusi besar pada perkembangan material science yang banyak dikaji karena menunjukan sifat yang unik. Berbagai macam penelitian dikembangkan untuk mengetahui sifat baru dari material nano. Salah satunya dengan cara memodifikasi morfologi maupun mengkombinasikan dengan material lain agar memiliki sifat yang lebih unggul (Y.Xia, 2003). Titania IV Oksida $\left(\mathrm{TiO}_{2}\right)$ merupakan salah satu material science yang menarik untuk dikaji dan dikembangkan dalam berbagai penelitian karena sifat yang dimilikinya. $\mathrm{TiO}_{2}$ yang memiliki sifat nontoksik menjadi salah satu pilihan utama untuk dikembangkannya dalam sintesis material berbahan $\mathrm{TiO}_{2}$ (Sekino, 2010).

Sol gel merupakan salah satu metode yang digunakan untuk melakukan synthesis nano $\mathrm{TiO}_{2}$. Selain mudah, metode sol gel banyak dipilih karena dapat digunakan untuk mengkontrol pembentukan fasa dan ukuran nano $\mathrm{TiO}_{2}$ Desong et al.,( 2011). Senyawa yang digunakan dalam sintesis $\mathrm{TiO}_{2}$ 
menggunakan metode sol gel adalah alkoksida TTiP yang berfungsi sebagai prekusor $\mathrm{Ti}$, pelarut, air sebagai media untuk proses hidrolisis dan larutan asam sebagai penstabil. Pada saat proses sol gel berlangsung terjadi perubahan fasa dari suspensi koloid membentuk fasa cair kontinyu yang akhirnya akan berubah menjadi padatan nanostruktur setelah dilakukan pengeringan (Mingwei et al., 2006). Menurut Behnajady et al., (2011) menyebutkan terdapat beberapa faktor yang berpengaruh terhadap proses pembentukan nanomaterial pada proses sol gel, diantaranya rasio hidrolisis (perbandingan mol TTiP dengan mol air), keasaman larutan dan salah satu faktor yang terpenting adalah penggunaaan jenis pelarut karena berpengaruh terhadap proses reaksi sol gel. Untuk itulah penelitian terkait jenis pelarut dalam sintesis nano $\mathrm{TiO}_{2}$ perlu dilakukan.

\section{METODE PENELITIAN}

\section{Bahan dan Alat}

TiPP (Titanium (IV) isopropoxide) kadar 97\% (Sigma-Aldrich), NaOH (Merck), $\mathrm{CH}_{3} \mathrm{COOH}$ (Merck), metanol, ethanol, Aquades, Indikator Universal (Merck) dan kertas saring.

\section{Preparasi sampel}

Preparasi nano $\mathrm{TiO}_{2}$ dilakukan menggunakan metode sol-gel dengan perkusor TTiP dan pelarut methanol untuk sampel A dan ethanol untuk sampel B. Ratio molar yang digunakan adalah 1:1 (solvent:metoksida TTiP). Langkah Pertama, menyiapkan $35 \mathrm{~mL}$ pelarut secara presisi dengan gelas ukur kemudian dibagi kedalam erlenmeyer $(30 \mathrm{~mL})$ dan beaker glass $(5 \mathrm{~mL}) .30 \mathrm{ml}$ pelarut kemudian ditambahkan $\mathrm{CH} 3 \mathrm{COOOH}$. Penambahan asam dilakukan sampai $\mathrm{pH} \pm 1$ diiringi dengan pengadukan menggunakan stirrer secara konstan selam 10 menit agar larutan terdistribusi merata. Suasana larutan dijaga cukup asam agar hidrolisis tidak berlangsung secara cepat. Setelah dilakukan pengadukan dilanjutkan dengan menambahkan TTiP sebanyak 4,13ml secara drop to drop, dilanjutkan dengan penambahan $(5 \mathrm{ml}$ pelarut $+0,252 \mathrm{ml}$ air) secara tetes demi tetes diikuti dengan pengadukan kontstan selama \pm 5 jam. Proses aging dilakukan selama 48 jam dan dilanjutkan dengan pengovenan. Kalsinasi $\mathrm{TiO} 2$ dilakukan pada suhu $450^{\circ} \mathrm{C}$ dilanjutkan dengan karakterisasi XRD. Terdapat 2 sampel dimana sampel A(metanol, AA); sampel B (etanol,AA).

Sampel C disintesis dengan cara 25 $\mathrm{mL}$ TTiP yang dilarutkan dalam $8 \mathrm{~mL}$ dengan diaduk magnetic stirrer. Kemudian campuran ditambahkan ke dalam $200 \mathrm{~mL}$ aquades dan diaduk selama 30 menit. Kemudian ditambahkan $3 \mathrm{~mL}$ HNO3 dan diaduk selama 60 menit, didiamkan selama 3 hari dalam suhu kamar. Gel yang didapat dikeringkan pada suhu $75^{\circ} \mathrm{C}$ selama 3 hari dan dikalsinasi pada suhu $400^{\circ} \mathrm{C}$ selama 2 jam (Mohamed et al., 2015). Ketiga sampel akan diuji menggunakan instrumen XRD guna mengetahui pengaruh pelarut dan asam terhadap kristalinitas dan ukuran partukel nano $\mathrm{TiO}_{2}$.

\section{HASIL DAN PEMBAHASAN}

Hasil sintesis nanopartikel $\mathrm{TiO}_{2}$ variasi pelarut dengan metode sol gel di uji menggunakan instrumen XRD. Gambar 1 menunjukkan difraktogram XRD Sampel A dan Sampel B.

Hasil karakterisasi XRD pada gambar 1 menunjukkan bahwa penggunaan pelarut berpengaruh terhadap kristalinitas dan fasa material yang terbentuk. Kristalinitas dan fasa suatu material merupakan salah satu karakter yang perlu diperhatikan untuk menentukan aplikasi dari suatu material (Bessekhouad et al., 2003). Difaktogram XRD pada gambar 1 menunjukkan bahwa penggunaan methanol meningkatkan kristalinitas nanopartikel $\mathrm{TiO}_{2}$.

Hal ini disebabkan karena pelarut yang berbeda akan mempunyai polaritas yang berbeda. Polaritas yang berbeda pada metanol dan etanol akan berpengaruh pada besarnya reaktivitas pada proses hidrolisis dan kondensasi (Behnajady et al., 2011). Kedua proses ini merupakan faktor yang berpengaruh terhadap keberhasilan sintesis nanopartikel $\mathrm{TiO}_{2}$ menggunakan metode solgel. 


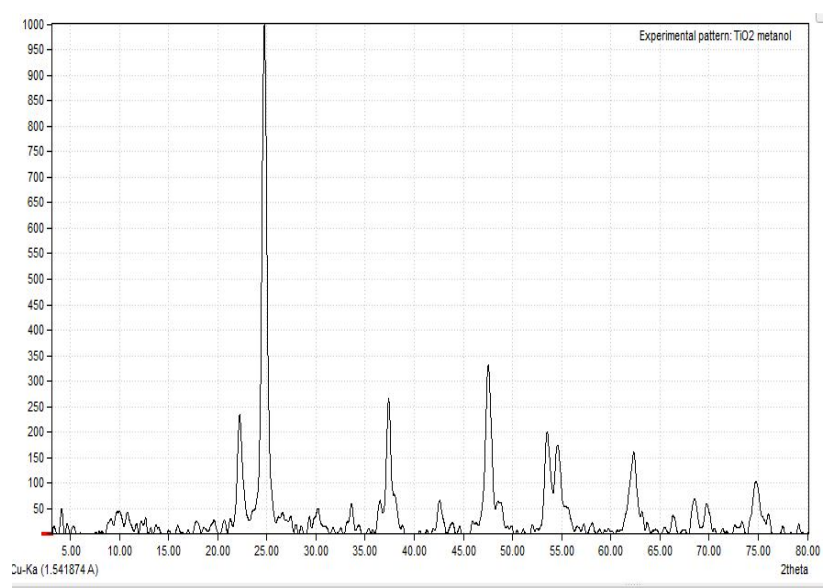

Sampel A

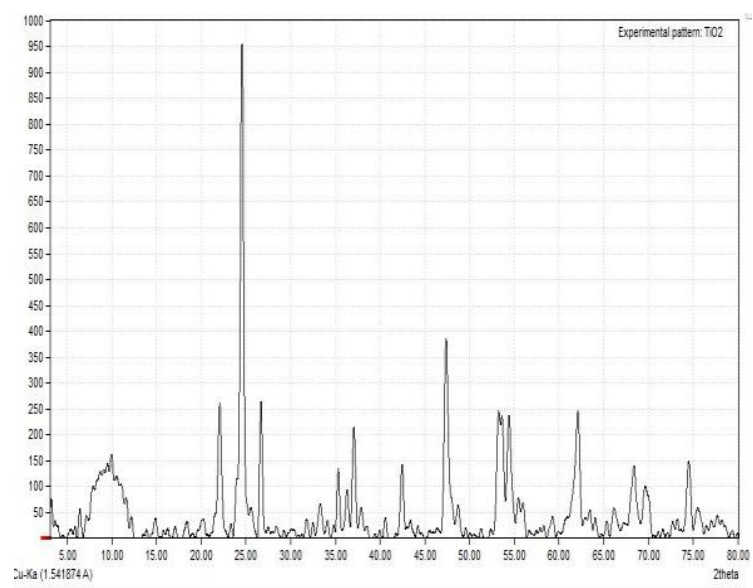

Sampel B

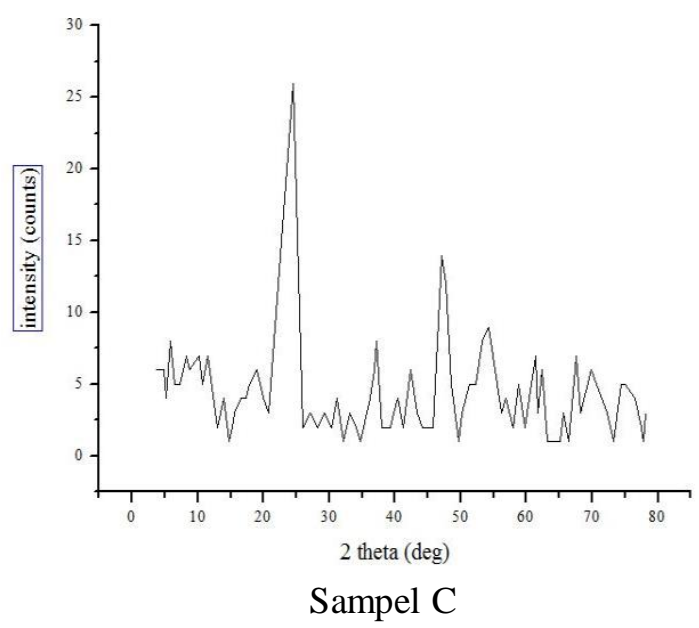

Gambar 1. Difraktogram XRD Nano $\mathrm{TiO}_{2}$ Sampel A, Sampel B, dan Sampel C

Berdasarkan JCPDS card nomor 84-1286 menunjukkan difraktogram nano $\mathrm{TiO}_{2}$ hasil sintesis sebagian besar merupakan fasa anatas. Hal ini terlihat dari nilai 2 teta yang diperoleh yaitu $24,45^{\circ} ; 47,29^{\circ} ; 53,18^{\circ} ; 61,64^{\circ}$ untuk fasa anatas dan $54,65^{\circ} ; 74,16^{\circ}$ untuk fasa rutil. Hanya saja persentase fasa anatas pada nano $\mathrm{TiO}_{2}$ menggunakan pelarut metanol lebih besar jika dibandingkan dengan hasil nano tio2 dengan pelarut etanol. Berdasarkan perhitungan ukuran partikel nano $\mathrm{TiO}_{2}$ menggunakan persamaan DebyeScherer didapatkan ukuran nano $\mathrm{TiO}_{2}$ menggunakan metanol sebesar $13.78 \mathrm{~nm}$ sedangkan nano tio2 menggunakn etanol sebesar $34.26 \mathrm{~nm}$

\section{Karakterisasi dengan TEM}

Berdasarkan Gambar 2 hasil karakterisasi TEM terlihat bahwa struktur nano $\mathrm{TiO}_{2}$ sudah terbentuk.

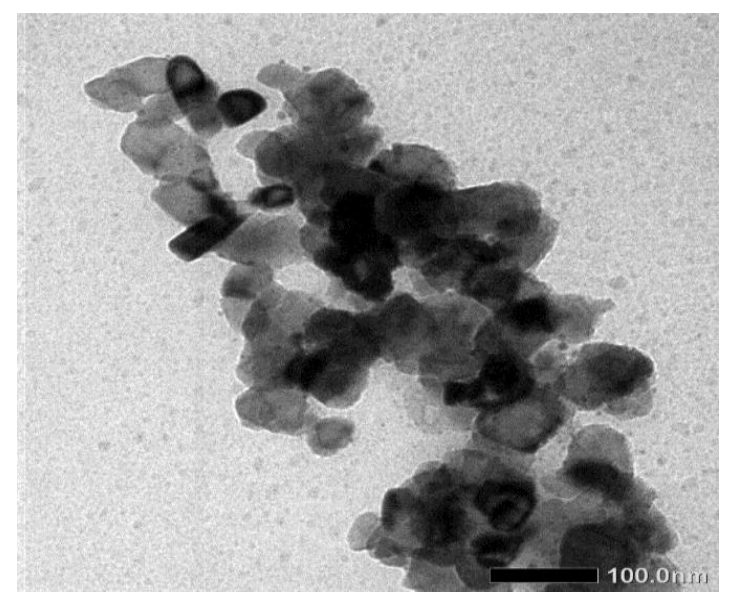

Gambar 2. Analisis nanopartikel $\mathrm{TiO}_{2}$ menggunakan pelarut metanol. 


\section{KESIMPULAN}

Pelarut pada proses sintesis nanopartikel $\mathrm{TiO}_{2}$ menggunakan metode sol gel berpengaruh terhadap kristalinitas dan ukuran partikel material.

\section{DAFTAR PUSTAKA}

Behnajady,M.A., Eskandarloo, H., Modirshahla, N., Shokri, M. 2011. Investigation of The Effect of SolGel Synthesis Variables on Structural and Photocatalytic Properties of $\mathrm{TiO} 2$ Nanoparticles. Journal of Desalination 278 (2011) 10-17.

Bessekhouad,Y., D. Robert., J.V.Weber. 2003. Synthesis of Photocatalytic TiO2 Nanoparticles: Optimization of The Preparation Conditions, $J$. Photochem. Photobiol. A 157 47-53.

Desong, W., Xiao, L., Luo, Q., Xiao, L \& Duan, Y. 2011. Highly Efficient Visible Light TiO2 Photocatalyst Prepared by Sol-Gel Method at Temperatures Lower than $300^{\circ} \mathrm{C}$. Journal of Hazardous Materials 192(1): $150-159$.
Mingwei, C., Ma, E \& Hemker, K. 2006. Mechanical Behavior of Nanocrystalline Metals. in Nanomaterials Handbook. Taylor \& Francis Group.

Sekino, T. 2010. Synthesis and Applicatios of Titanium Oxide Nanotubes. Journal of Inorganic and Metalic Nanotubular Materials 117: 17-32.

Xia, P. Y., Sun, Y., Wu, Y., Mayers, B., Gates, B., Yin, Y., Kim, F \& Yan, H. $2003 . \quad$ One-Dimensional Nanostructures: Synthesis, Characterization, and Applications. Journal of Advanced Materials. 15(5): 353-389. 